\title{
Órgano administrativo competente para conocer del recurso especial en materia de contratación pública en Castilla y León
}

\author{
José Carlos Laguna de Paz \\ Catedrático de Derecho Administrativo \\ Universidad de Valladolid \\ laguna@der.uva.esl
}

\begin{abstract}
Resumen
En su intento por cumplir con las exigencias europeas, el legislador estatal ha introducido un recurso administrativo especial en materia de contratación pública, cuya resolución se encarga a un órgano administrativo independiente. No obstante, su regulación se entrega a las CCAA. En este contexto, Castilla y León prevé la creación del Tribunal Administrativo de Recursos Contractuales, que-como singularidad-se adscribe al Consejo Consultivo de la $C A$.
\end{abstract}

Palabras clave Contratación pública (public procurement), recurso, órgano independiente.

\section{The Special Public Procurement Review Authority of Castilla y León}

\begin{abstract}
In an effort to comply with European requirements, the State legislator has introduced a special administrative review for public procurement matters, entrusting an independent administrative authority with the task of settling the disputes. However, the autonomous regions are entrusted with the task of regulating them. In this context, Castilla y León plans to introduce a Public Procurement Review Administrative Court, with the peculiarity of being attached to the Consultative Council of the Autonomous Region.
\end{abstract}

Key words

Public procurement, review, independent authority. 


\section{SU REGULACIÓN CORRESPONDE A LAS CCAA}

1. El afán por cumplir las que se entienden exigencias de la normativa europea' nos está llevando a desfigurar nuestra legislación contractual pública, que siempre ha gozado de una calidad contrastada.

Como es natural, la tutela cautelar se vincula a la discusión del fondo del asunto. No tiene mucho sentido solicitar medidas provisionales sin discutir la legalidad de la actuación del poder adjudicador. De ahí que sea más que discutible la apreciación de que las medidas cautelares previstas en nuestro ordenamiento jurídico no permitieran asegurar la protección efectiva de los interesados ${ }^{2}$. A este respecto, es suficiente con recordar nuestra jurisprudencia constitucional, que conecta la tutela cautelar con el derecho a la tutela judicial efectiva (art. 24 CE)3. También los remedios que ofrece nuestra legislación, que permite adoptar medidas cautelares -si es necesario, de carácter positivo- de manera urgente (inaudita parte) (arts. 129 y ss. LJCA).

Es también discutible que la exigencia europea de disponer de un medio de reacción que permita al interesado anular la decisión del órgano de contratación con carácter previo a la ejecución (“celebración”) del contrato4, que es el efecto útil que persigue la Directiva ${ }^{5}$, nos haya llevado a romper la regla tradicional ${ }^{6}$ en nuestro orde-

1 La normativa europea está constituida por: (i) Directiva 89/665/CEE del Consejo, de 21.12.1989, relativa a la coordinación de las disposiciones legales, reglamentarias y administrativas referentes a la aplicación de los procedimientos de recurso en materia de adjudicación de los contratos públicos de suministros y de obras; (ii) Directiva 92/13/CEE del Consejo, de 25.2.1992, relativa a la coordinación de las disposiciones legales, reglamentarias y administrativas referentes a la aplicación de las normas comunitarias en los procedimientos de formalización de contratos de las entidades que operen en los sectores del agua, de la energía, de los transportes y de las telecomunicaciones. Estas normas han sido modificadas por la Directiva 2007/66/CE del Parlamento Europeo y del Consejo, de 11.12.2007, por la que se modifican las Directivas 89/665/CEE y 92/13/CEE del Consejo en lo que respecta a la mejora de la eficacia de los procedimientos de recurso en materia de adjudicación de contratos públicos.

2 STJCE de 15.5.2003, asunto C-214/00: “(... ) si bien la normativa española establece la posibilidad de que se adopten medidas cautelares de carácter positivo, no cabe considerar que constituya un sistema de tutela judicial provisional adecuado para corregir de manera eficaz las infracciones eventualmente cometidas por las entidades adjudicadoras, dado que exige por regla general la interposición previa de un recurso en cuanto al fondo como condición para la adopción de una medida provisional contra una decisión de la entidad adjudicadora" (marginal 99); “Esta apreciación no queda desvirtuada por el hecho de que, en el marco de la suspensión en vía judicial, el recurso pueda interponerse mediante un simple escrito y que la demanda pueda formalizarse posteriormente a la solicitud de la medida cautelar, dado que la exigencia de que se cumpla previamente una formalidad de este tipo tampoco puede considerarse compatible con las prescripciones de la Directiva 89/665 (...)" (marginal 100).

3 STC de 12.12.1991; STC de 10.2.1992; STC de 17.12.1992; STC de 29.4.1994.

4 "Cuando se someta a un órgano de primera instancia independiente del poder adjudicador un recurso referente a una decisión de adjudicación de un contrato, los Estados miembros garantizarán que el poder adjudicador no pueda celebrar el contrato hasta que el órgano que examine el recurso haya tomado una decisión sobre la solicitud de medidas provisionales o sobre el fondo del recurso" (art. 2.3 de la Directiva 89/665/CEE, en su redacción de la Directiva 2007/66/CE).

5 STJCE de 3.4.2008, C-444/06.

6 De Los Mozos Touya, I., El enigma del contrato público, en g. Ariño Ortiz (Liber amicorum),

184 “Derecho Administrativo y regulación económica”, La Ley, 2011, p. 376. 
namiento jurídico de que el acto administrativo de adjudicación perfecciona el contrato. A estos efectos, hubiera bastado con establecer un plazo mínimo para la formalización, que seguiría siendo un mero requisito de eficacia?.

Finalmente, es también discutible que la mejor forma de cumplir con las garantías que establece la normativa europea en materia de recursos sea la creación de un órgano administrativo independiente. Hubiera sido mejor garantizar en todo caso la posibilidad de acceso directo a la jurisdicción contencioso-administrativa, lo que simplemente hubiera requerido hacer potestativa la alzada, en los pocos supuestos en que es preciso interponer este recurso en materia de contratación. No obstante, el legislador ha preferido crear un recurso administrativo especial, que da lugar a una nueva colección de estructuras administrativas, estatales y autonómicas. Aunque cueste trabajo creerlo, en el ámbito autonómico, con carácter previo al recurso especial, la normativa puede establecer aún otro recurso administrativo [art. 41.3, párrafo $2^{\circ}$, del Real Decreto Legislativo 3/2011, de 14.11, por el que se aprueba el texto refundido de la Ley de Contratos del Sector Público (TrLCSP)].

2. En este contexto, en ejercicio de sus atribuciones constitucionales, el Estado regula el régimen del recurso especial en materia de contratación pública. No obstante, encomienda a las CCAA decidir el órgano a quien competa resolver dicho recurso (art. 40.3 TrLCSP) ${ }^{8}$ y art. 101 de la Ley 31/2007, de 30.10, sobre procedimientos de contratación en los sectores del agua, la energía, los transportes y los servicios postales (LCSExcl)]. Con ello, el legislador estatal respeta una de las más características atribuciones autonómicas, como es la de autoorganización (art. 148.1.1 ${ }^{\text {a }}$ CE).

\section{AL TIEMPO QUE SE REDACTAN ESTAS PÁGINAS, UN MANDATO INCUMPLIDO}

3. La disposición final $7^{\text {a }}$ de la Ley $19 / 2010$, de 22.12, de medidas financieras y de creación del Ente Público Agencia de Innovación y Financiación Empresarial de Castilla y León, encomendó a la Junta la creación de un órgano con competencia para la resolución de las impugnaciones para la resolución del recurso especial en materia de contratación?.

A este respecto, el Anteproyecto de Ley de medidas financieras (AnteprLMF) crea el Tribunal Administrativo de Recursos Contractuales de Castilla y León. No obstante, la convulsión administrativa suscitada por la crisis financiera internacional quizá contribuya a explicar que, casi un año después, el mandato del legislador siga sin cumplirse.

7 Martínez López-Muñiz, J.L., El nacimiento de los contratos públicos: reflexiones sobre una equivocada transposición de la Directiva comunitaria “de recursos”, RAP, 185, 2011, p. 341.

8 La regulación que establece en este punto el TrLCSP tiene carácter básico, con excepción del art. 41.1 y 3 (disposición final $2^{\mathrm{a}} .3$ TrLCSP).

9 En este contexto, la Consejera de Hacienda de la CA declaró que la Ley de Medidas para el año 2012 crearía el Tribunal Administrativo de Recursos Contractuales de Castilla y León. 
4. Mientras tanto, resulta de aplicación la Disposición Transitoria $7^{\mathrm{a}} \operatorname{TrLCSP}$, que dispone el régimen aplicable hasta que las CCAA regulen la materia. En concreto:

- Se establece que la competencia para la resolución de los recursos continuará encomendada a los mismos órganos que la tuvieran atribuida con anterioridad.

- Los recursos se tramitarán de conformidad con lo establecido en los arts. 42 a 48 TrLCSP o, en su caso, en los arts. 103-108 de la Ley 31/2007.

- Las resoluciones dictadas en estos procedimientos serán susceptibles de recurso contencioso-administrativo. Cuando no sean totalmente estimatorias o cuando hubiesen comparecido en el procedimiento otros interesados distintos del recurrente, no serán ejecutivas hasta que sean firmes o, si hubiesen sido recurridas, hasta tanto el órgano jurisdiccional competente no decida acerca de su suspensión.

\section{LA NORMATIVA DEJA UN ENORME MARGEN DE DECISIÓN A LAS CCAA}

5. Como hemos avanzado, la legislación estatal es exquisitamente respetuosa con las atribuciones autonómicas. En caso de que decidan crear un órgano propio, simplemente, habrán de observar dos exigencias, que la normativa española parece entender derivadas del Derecho europeo ${ }^{10}$ (art. 40.3 TrLCSP):

(i) Un estatus que garantice la independencia del órgano: "El nombramiento de los miembros de esta instancia independiente y la terminación de su mandato estarán sujetos en lo relativo a la autoridad responsable de su nombramiento, la duración de su mandato y su revocabilidad a condiciones que garanticen su independencia e inamovilidad".

(ii) Capacitación técnica: el titular del órgano, o en el caso de que fuera colegiado al menos su Presidente, ha de ostentar cualificaciones jurídicas y profesionales que garanticen un adecuado conocimiento de las materias de que deba conocer.

6. El amplio margen de decisión con que cuentan las CCAA debe permitirles dotarse de la solución organizativa que entiendan más eficiente y eficaz. Entre otros factores, deberán valorar la previsible carga de trabajo que vaya a tener el órgano encargado de resolver los recursos. A este respecto, conviene llamar la atención acer-

10 En realidad, el art. 2.9 de la Directiva 89/665/CEE, en su redacción de la Directiva 2007/66/CE, sólo impone estas exigencias a los órganos competentes para conocer de las decisiones adoptadas por órganos no jurisdiccionales que tengan encomendados los recursos frente a los actos del poder adjudicador. 
ca de la inconveniencia de que las CCAA -como ha sucedido en otros muchos ámbitos- tiendan a reproducir miméticamente soluciones organizativas que pueden no estar justificadas por sus dimensiones o necesidades. En particular, hay que tener en cuenta que:

- La contratación pública, que es una de las potestades públicas que mueven un porcentaje mayor de recursos, tradicionalmente, ha dado lugar a una relativamente reducida conflictividad judicial.

- Además, el recurso administrativo especial en materia de contratación pública tiene carácter potestativo (art. 40.6 TrLCSP), lo que significa que los interesados podrán acudir directamente a la jurisdicción contencioso-administrativa en defensa de sus derechos (salvo que la decisión del poder adjudicador no ponga fin a la vía administrativa).

- Finalmente, las CCAA podrían incluso prever un recurso administrativo previo al recurso especial en materia de contratación pública (art. 41.3, párrafo $\left.2^{\circ}, \operatorname{TrLCSP}\right)$.

En este contexto, la propia normativa estatal brinda a las CCAA la posibilidad de atribuir la competencia al órgano estatal, que es el Tribunal Administrativo Central de Recursos Contractuales, adscrito al Ministerio de Economía y Hacienda (art. 41.1, párrafo $2^{\circ}$, TrLCSP). A estos efectos, deberá celebrarse el correspondiente convenio con la Administración General del Estado, en el que se estipulen las condiciones en que la CA sufragará los gastos derivados de esta asunción de competencias.

En este caso, la única cuestión a despejar es de qué técnica jurídica estamos hablando. Desde luego, no se trata de una encomienda de gestión, que sólo permite trasladar el ejercicio de tareas de carácter material o técnico (art. 15.1 LRJPAC), pero que no supone la cesión de la titularidad de la competencia ni de los elementos esenciales de su ejercicio (art. 15.2 LRJPAC). Se trataría más bien de una suerte de delegación del ejercicio de la competencia de sentido ascendente, cuya admisibilidad resultaría de su explícita previsión legislativa. Con ello, se suscita la duda de cuál sería el régimen de recursos frente a los actos que dictara el órgano administrativo estatal. La solución más conforme con el sistema parece que debe ser afirmar la competencia de los órganos judiciales a quienes corresponda conocer de los actos dictados por la Administración autonómica.

\section{EL ANTEPROYECTO DE LEY CONTEMPLA LA CREACIÓN DE UN ÓRGANO ADMINISTRATIVO VINCULADO AL CONSEJO CONSULTIVO DE LA COMUNIDAD AUTÓNOMA}

7. El Anteproyecto de Ley de medidas financieras (AnteprLMF) crea el Tribunal Administrativo de Recursos Contractuales de Castilla y León, al que se atribuye la 
competencia para conocer de los recursos especiales en materia de contratación pública (art. 35).

8. La singularidad de la propuesta radica en que el Tribunal se adscribe al Consejo Consultivo de Castilla y León (art. 39 AntepLMF), que -con cargo a su presupuestole proveerá de los necesarios medios materiales y personales (art. 40 AntepLMF).

En concreto, el Tribunal:

- Estará compuesto por un Presidente y dos Vocales, más un Secretario, que tendrá voz, pero no voto (art. 37.1 AnteprLMF).

- Será Presidente del Tribunal el del Consejo Consultivo de Castilla y León (art. 37.2 AnteprLMF). En caso de ausencia, vacante o enfermedad del Presidente, éste será sustituido por el vocal de mayor edad.

- Los vocales del Tribunal se nutrirán de Consejeros electivos del Consejo Consultivo de Castilla y León (art. 37.3 AnteprLMF).

- El Secretario General del Consejo Consultivo será también Secretario del Tribunal, aunque no tendrá la condición de miembro de este órgano colegiado (art. 37.4 AnteprLMF). En caso de ausencia, vacante o enfermedad, será sustituido por el miembro del Tribunal de menor edad, a excepción del Presidente.

- Las resoluciones se adoptarán por mayoría de votos de los miembros del órgano y en caso de empate decidirá el Presidente, con voto de calidad (art. 38 AntepLMF).

9. Como puede verse, la propuesta de la CA está presidida por la idea de la eficiencia y austeridad en el gasto público, tan necesaria no solo en tiempos de crisis. Hay que tener en cuenta que los miembros del Tribunal, así como su Secretario no percibirán retribución adicional alguna por su pertenencia a éste órgano (art. 37.5 AnteprLMF). Se trata, por tanto, de la asunción de una nueva función administrativa a coste cero. No obstante, la cuestión es si la adscripción orgánica del Tribunal al Consejo Consultivo respeta también las exigencias de independencia y capacitación profesional exigidas por la normativa europea y estatal ${ }^{11}$.

10. En particular, el Tribunal se beneficia de la propia independencia del Consejo Consultivo respecto de la Administración de la CA, que resulta de los siguientes elementos:

11 Con fecha de 11.10.2011, el Consejo Consultivo de Castilla y León emitió dictamen al Anteproyecto de Ley, valorando positivamente esta solución: “Con carácter general, puede afirmarse que la regulación contenida en el anteproyecto de ley cumple con lo previsto en la LCSP (órgano independiente, cualificación jurídica y profesional, independencia e inamovilidad de los miembros del órgano) y recoge las menciones mínimas que el artículo 53.1 de la Ley 3/2001, de 3 de julio, del Gobierno y de la Administración de la Comunidad de Castilla y León, exige para la creación de órganos colegiados en la Administración de la Comunidad" [http://www.cccyl.es/index.php?option=com_remository\&ltemid=67\&func=fileinfo\&id=9203]. 
- El Consejo Consultivo es el superior órgano consultivo de la Junta y de la Administración de la CA (art. 33.1 de la Ley Orgánica 4/1983, de 25.2, Estatuto de Autonomía de Castilla y León).

- Ejerce sus funciones con autonomía, orgánica y funcional, con el fin de garantizar la objetividad e independencia de su actuación [art. 1.2 Ley 1/2002, de 9.4, reguladora del Consejo Consultivo de Castilla y León (LCConsult)].

- Los Consejeros electivos son designados por las Cortes de Castilla y León, a propuesta de los grupos parlamentarios (art. 7.2 LCConsult), por un período de seis años desde la fecha de su designación (art. 7.5 LCConsult). Los consejeros natos responden a la condición objetiva de ser ex Presidentes de la Junta de Castilla y León (art. 7.4 LCConsult).

- Sus miembros están sujetos a un riguroso régimen de incompatibilidades, cuya condición no permite desarrollar ningún otro cargo público o administrativo, ni el ejercicio de actividades profesionales (art. 11 LCConsult).

- Sus dictámenes se fundamentarán en Derecho, sin que puedan extenderse a valoraciones de oportunidad o conveniencia, salvo que así le sea expresamente solicitado por la autoridad consultante (art. 2.1 LCConsult).

Los órganos consultivos pueden también asumir competencias jurisdiccionales, como sigue sucediendo con el Consejo de Estado francés. No obstante, en la regulación proyectada, el Tribunal no se confunde con el Consejo Consultivo de la CA, sino que es un órgano vinculado a este, pero que actuará con plena independencia funcional: "El Tribunal actuará con separación de sus funciones respecto de las que corresponden al Consejo Consultivo en cuanto superior órgano consultivo de la Comunidad Autónoma y con plena independencia del resto de sus órganos, ejerciendo las funciones y dictando las resoluciones que correspondan" (art. 39, párrafo $2^{\circ}$, AnteprLMF). Corresponde al propio Tribunal la elaboración y aprobación de su propio reglamento de funcionamiento interno (art. 41 AnteprLMF).

Cuando los órganos que hayan de conocer los recursos no sean de carácter jurisdiccional, la normativa europea exige que no sólo el nombramiento, sino también la duración del mandato y las condiciones de revocabilidad de los miembros del órgano administrativo sean equiparables a las de los jueces ${ }^{12}$. A estos efectos, en el ámbito estatal, el art. 41.1 TrLCSP dispone que los miembros del órgano -que son nombrados por seis años- tendrán carácter independiente e inamovible, y no podrán ser removidos sino por una serie de causas tasadas. Estas exigencias se proyectan también como mandatos al legislador autonómico (art. 41.3 TrLCSP). En cambio, el Anteproyecto no dice nada acerca de la duración del mandato de los vocales del Tribunal, ni de

12 Art. 2.9, in fine, de la Directiva 89/665/CEE, en su redacción de la Directiva 2007/66/CE. 
las causas de revocación. No obstante, no hay que olvidar que el objetivo a conseguir es la independencia del órgano que resuelve el recurso frente al poder adjudicador. De ahí que las garantías que introduce la legislación estatal pueden entenderse esenciales cuando el nombramiento de los miembros del órgano corresponde a la Administración de la CA, pero no cuando la designación es competencia de un órgano independiente, como es el Consejo Consultivo.

11. La segunda cuestión es si el Anteproyecto también satisface los requisitos de cualificación jurídica y profesional. A este respecto, hay que recordar que la normativa europea y estatal exigen que, como mínimo, el Presidente del órgano ostente cualificaciones jurídicas y profesionales que garanticen un adecuado conocimiento de las materias a resolver. En realidad, podría exigirse la capacitación jurídica de todos sus integrantes, ya que se trata de un órgano especializado en la resolución de recursos administrativos, en los que no se ventilan cuestiones de oportunidad, sino de estricta legalidad (art. 107.1 LRJPAC).

A este respecto, en el anteproyecto se prevé que el cargo de Presidente del Tribunal coincida con el del Consejo Consultivo. Hay que tener en cuenta que este último es elegido entre los miembros electivos de este órgano (art. 8 LCConsult). En caso de vacante o ausencia del Presidente, ejercerá sus funciones el Consejero electivo más antiguo, y si concurriesen varios de la misma antigüedad, el de mayor edad.

En la mayor parte de los casos, los Consejeros electivos serán idóneos, ya que se trata de personas designadas por las Cortes de Castilla y León a propuesta de los Grupos Parlamentarios (art. 7.2 LCConsult), entre licenciados en Derecho con más de diez años de dedicación a función o actividad profesional de contenido jurídico (art. 7.3 LCConsult). No obstante, excepcionalmente, el Reglamento orgánico podrá contemplar la posibilidad de acceso a la condición de Consejero de otros titulados superiores que, aun no siendo licenciados en Derecho, acrediten una reconocida competencia en relación con las funciones del Consejo (art. 7.3, in fine, LCConsult).

En conclusión, no puede, pues, excluirse que la elección pueda recaer sobre una persona que no tenga la condición de jurista. De ahí que el anteproyecto debería prever una solución para este supuesto de posible inidoneidad.

\section{COMPETENCIA SUBJETIVA DEL TRIBUNAL: CONTRATACIÓN DE LA ADMINISTRACIÓN AUTONÓMICA, LOCAL Y -EN SU CASO- DE LOS DEMÁS PODERES PÚBLICOS AUTONÓMICOS}

12. El Tribunal ejerce su competencia respecto de los contratos que realicen los siguientes órganos y entidades (art. 39, párrafo $3^{\circ}$, AnteprLMF):

(i) Órganos, entes, organismos y entidades de la CA de Castilla y León que tengan la condición de poder adjudicador. 
(ii) Órganos y entidades de las Corporaciones locales integradas en el ámbito territorial de la CA.

A este respecto, la legislación estatal dispone que la competencia para resolver los recursos será establecida por las normas autonómicas cuando éstas tengan atribuida competencia normativa y de ejecución en materia de régimen local y contratación (art. 41.4 TrLCSP). En caso de que la normativa autonómica no se pronuncie, la competencia corresponderá al mismo órgano al que las CCAA hayan atribuido la competencia para resolver los recursos de su ámbito.

(iii) Las Cortes de Castilla y León, el Procurador del Común y el Consejo de Cuentas podrán acudir al Tribunal, previa celebración del correspondiente convenio con el propio Tribunal, para encomendarle la tramitación y resolución de los recursos, solicitudes de adopción de medidas provisionales y cuestiones de nulidad de los actos que constituyen el objeto del recurso especial.

En realidad, el propio legislador podría atribuir directamente al Tribunal la competencia para conocer de los recursos especiales a que pueda dar lugar la actuación de estos otros Poderes públicos. No es posible que éstos puedan articular órganos administrativos propios en esta materia, por lo que con ello- se ahorrarían costes de gestión. En esta línea, el legislador estatal reconoce al órgano estatal la competencia para resolver los recursos frente a los actos del Consejo General del Poder Judicial, del Tribunal Constitucional y del Tribunal de Cuentas (art. 41.1 TrLCSP), aunque respeta la autonomía de las Cortes Generales (art. 41.2 TrLCSP).

13. Cuando se trate de poderes adjudicadores que no tengan la consideración de Administraciones públicas, la competencia estará atribuida al órgano independiente que la ostente respecto de la Administración a que esté vinculada la entidad autora del acto recurrido (art. 41.5, párrafo $1^{\circ}, \operatorname{TrLCSP}$ ). Si la entidad contratante estuviera vinculada con más de una Administración, el órgano competente para resolver el recurso será aquél que tenga atribuida la competencia respecto de la que ostente el control o participación mayoritaria y, en caso de que todas o varias de ellas, ostenten una participación igual, ante el órgano que elija el recurrente (art. 41.5, párrafo $1^{\circ}$, TrLCSP).

En los contratos subvencionados, la competencia corresponderá al órgano independiente que ejerza sus funciones respecto de la Administración a que esté adscrito el ente u organismo que hubiese otorgado la subvención, o al que esté adscrita la entidad que la hubiese concedido, cuando ésta no tenga el carácter de Administración Pública (art. 41.6 TrLCSP). En el supuesto de concurrencia de subvenciones por parte de distintos sujetos del sector público, la competencia se determinará atendiendo a la subvención de mayor cuantía y, a igualdad de importe, al órgano ante el que el recurrente decida interponer el recurso de entre los que resulten competentes. 


\section{COMPETENCIA OBJETIVA DEL TRIBUNAL}

14. El Tribunal asume competencias para (art. 36 AnteprLMF):

a) El conocimiento y resolución de los recursos especiales en materia de contratación, y de las reclamaciones a que se refieran los arts. 310 LCSP [art. 40 TrLCSP] y $101 \mathrm{LCSExCl}$.

b) La adopción de decisiones sobre la solicitud de medidas provisionales [arts. 313 LCSP (art. 43 TrLCSP) y 103 LCSExcl].

c) La tramitación del procedimiento y la resolución de las cuestiones de nulidad contractual en los supuestos especiales establecidos en los arts. 37 LCSP y 109 LCSExCl.

Los actos recurribles y las declaraciones de nulidad contractual, así como el régimen de legitimación, interposición, planteamiento, tramitación, resolución, efectos y consecuencias jurídicas de los procedimientos serán los establecidos en la LCSP y en la LCSExcl.

Desde su constitución, el Tribunal será competente para resolver los procedimientos pendientes de resolución a la fecha de la entrada en vigor de la norma proyectada (disposición transitoria $3^{\mathrm{a}}$ AnteprLMF). 